\title{
Hyperspherical Coordinate Potential Energy Surface for the $\mathrm{He}_{3}$ Complex
}

\author{
Albernaz, A. F.; * Barreto, P. R. P. \\ Rev. Virtual Quim., 2016, 8 (2), 338-355. Data de publicação na Web: 13 de março de 2016 \\ http://rvq.sbq.org.br
}

\section{Superfície de Energia Potencial em Coordenadas Hiperesféricas do Complexo $\mathrm{He}_{3}$}

Resumo: Neste trabalho, mostramos uma nova Superfície de Energia Potencial (SEP) para o complexo $\mathrm{He}_{3}$. A SEP foi obtida em termos das coordenadas hiperesféricas. $\mathrm{O}$ potencial empregado tem uma forma analítica bem definida e muito simples. A dependência radial é obtida considerando três configurações principais, para as quais as energias foram calculadas usando os níveis $\operatorname{CCSD}(T)$ e $\mathrm{MRCl}$ e seis diferentes conjuntos de funções de base (aug-cc-pVXZ (X $=D, T, Q, 5,6)$ e d-aug-cc-pVQZ) e ajustada a uma função de Rydberg Generalizada.

Palavras-chave: Superfície de Energia Potencial; Complexo de van der Waals; Complexo $\mathrm{He}_{3}$; Coordenadas Hiperesféricas.

\section{Abstract}

In this work, we show a new Potential Energy Surface (PES) for the $\mathrm{He}_{3}$ complex. The PES was obtained using hyperspherical coordinates. The potential employed has a well defined and very simple analytical form. The radial dependence was obtained by considering three "leading" configurations whose energies, computed at CCSD(T) and $\mathrm{MRCl}$ levels and six different basis sets (aug-cc-pVXZ (X=D,T,Q,5,6) and d-aug-cc-pVQZ), were fitted by a Rydberg function.

Keywords: Potential Energy Surface; van der Waals Complex; $\mathrm{He}_{3}$ complex; Hyperspherical Coordinate.

\footnotetext{
* Universidade de Brasília, Instituto de Física, Campus Universitário Darcy Ribeiro, CEP 70910900, Brasília-DF, Brasil.

M albernazalessandra@gmail.com

DOI: $\underline{10.5935 / 1984-6835.20160025}$
} 


\title{
Hyperspherical Coordinate Potential Energy Surface for the $\mathrm{He}_{3}$ complex
}

\author{
Alessandra Ferreira Albernaz, ${ }^{a}$ Patrícia R. P. Barreto ${ }^{b}$ \\ a Universidade de Brasília, Instituto de Física, Campus Universitário Darcy Ribeiro, CEP 70910- \\ 900, Brasília-DF, Brasil. \\ ${ }^{b}$ Instituto Nacional de Pesquisas Espaciais, LAP, S. José dos Campos-SP, Brasil. \\ * albernazalessandra@gmail.com
}

Recebido em 13 de março de 2016. Aceito para publicação em 13 de março de 2016

\section{Introduction}

2. Theoretical and Computional Details

2.1. Analytic Function For The Three-Body potential

\section{Results and Discussion}

\subsection{Potential Energy Surface Fit}

\section{Conclusions}

\section{Introduction}

Helium has long been considered to be one of the most promising candidates for seeing Efimov physics since the ${ }^{4} \mathrm{He}$ dimer has a large scattering length larger than 200 a.u.. The theoretical treatment of triatomic ${ }^{4} \mathrm{He}$ systems is simple compared to other atomic species because there exists only one dimer bound state which has zero orbital angular momentum $l=0 .{ }^{1-7}$ Efimov states are highly exotic as they result when there is a zero or near-zero energy two-body bound state. ${ }^{5-8}$

Several studies appeared in the last decades employing different approaches and computational levels. ${ }^{8-12}$ Hyperspherical methods have been applied extensively to a wide range of dynamical problems for nuclear, atomic, and molecular systems involving three or more particles. ${ }^{8-15}$ Helium clusters are a subject of great interest and constitute a growing challenge for the theorists. ${ }^{9,10,14,15}$

Throughout the experiment conducted by Schöllkopf and Toennies with helium dimer, was also observed the existence of the $\mathrm{He}$ trimers. ${ }^{16}$ The Cencek et. al. found an equilateral configuration with $R_{e}=2.9634 \AA$ (5.6 $a_{0}$ ) near the minimum of the total potential, the nonadditive three-body energy calculated at the $\mathrm{FCl}$ level amounts to 88.5 $\mathrm{mK}\left(0.0612 \mathrm{~cm}^{-1}\right),{ }^{17}$ compared to $98.5 \mathrm{mK}$ $\left(0.0666 \mathrm{~cm}^{-1}\right)$ at the coupled cluster with single, double, and noniterative triple excitations $\operatorname{CCSD}(\mathrm{T})$ level. ${ }^{18}$

Since the first work on $\mathrm{He}_{3}$ in $1972,{ }^{19}$ several theoretical papers have been published using variety of methods and coordinate systems: Monte Carlo, ${ }^{20,21}$ specific functions, ${ }^{22}$ and hyperspherical coordinates. ${ }^{23}$ 
Nevertheless, unfortunately, an analytic form of the Potential Energy Surface - PES simple enough to be used for all the purposes is still missing. ${ }^{8-10}$

In this paper, to fill the above gap, we present a very simple and accurate analytical expression of the PES.This function, which is express in terms of a hyperspherical coordinate system, is capable of treating reactive systems, ${ }^{11}$ vibrations of three body systems, ${ }^{12,13}$ molecules of ABA type, ${ }^{14}$ as well as van der Waals complexes. ${ }^{15}$

The paper is organized as follows. In Section 2 theoretical and computational details are given. In Section 3 results are presented and discussed. Conclusions follow in Section 4.

\section{Theoretical and Computional Details}

\subsection{Analytic Function For The Three- Body potential}

The coordinate system is made by three variable, the hyperradius and two hyperangles. The hyperangle $\Theta$ represents the area of the triangle and the hyperangle $\Phi$ is related with the shape of it, the hyperradius, $\rho$, is the vector pointed out from the center-of-mass (CM) of the system, see Figure 1. In this figure, the vectors $\boldsymbol{r}_{\boldsymbol{i}}\left(\boldsymbol{x}_{\boldsymbol{i}}, \boldsymbol{y}_{\boldsymbol{i}}, \boldsymbol{z}_{\boldsymbol{i}}\right)(i=1,2$ and 3$)$ representing the interatomic distances in space. A full description of hyperspherical coordinates was presented in 1986 by Aquilanti et. al. ${ }^{16}$ and then, these coordinates have been extensively used to described several sistems. ${ }^{20,23-26,28-30}$

In previous works we used the spherical and hyperspherical coordinates for the representation of the potential energy surface for various van der Waals $\mathrm{H}_{2} \mathrm{O}_{2} \cdots X$ and $\mathrm{H}_{2} \mathrm{~S}_{2} \cdots \mathrm{X}$, with $\mathrm{X}=\mathrm{He}, \mathrm{Ne}, \mathrm{Ar}, \mathrm{Kr}$ and $\mathrm{Xe}$ and for $\mathrm{H}_{2} \mathrm{O} \cdots \mathrm{X}_{2}$, with $\mathrm{X}=\mathrm{H}, \mathrm{N}$ and $\mathrm{O}$ systems. ${ }^{25-28}$ Using the same methodology, we propose here a new PES for the $\mathrm{He}_{3}$ complex. More in detail we have obtained the PES using the mass unscaled hyperspherical coordinates, see Figure 1, $\rho>0,0 \leq \Theta \leq \frac{\pi}{4}, 0 \leq \Phi \leq \frac{\pi}{3}$. Note that the ranges of $\Theta$ and $\Phi$ are lower than their standard values. Symmetry restrictions are indeed needed to account for the exchange of identical particles.

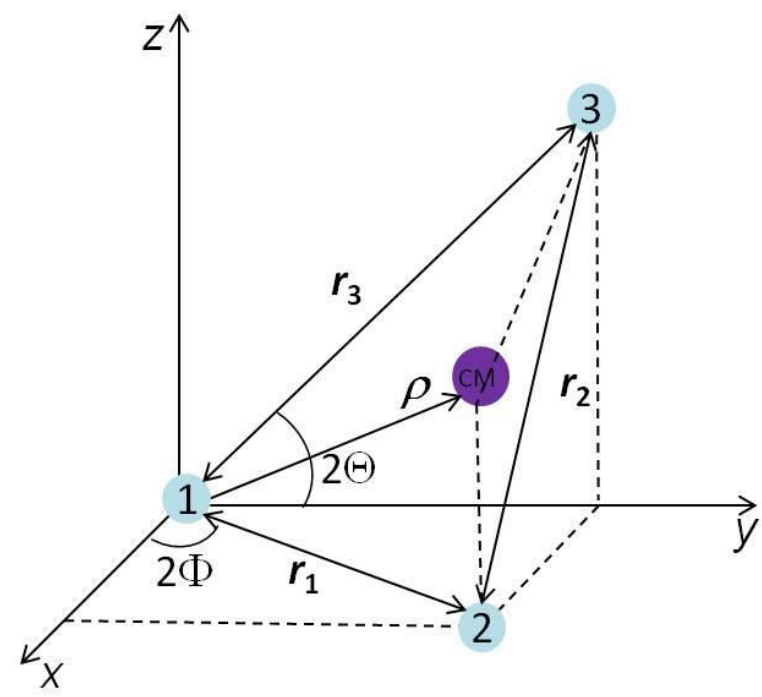

Figure 1. Definition of the hyperspherical coordinates $(\rho, \Theta, \Phi)$. The vector $\boldsymbol{r}_{\boldsymbol{i}}\left(\boldsymbol{x}_{\boldsymbol{i}}, \boldsymbol{y}_{\boldsymbol{i}}, \boldsymbol{z}_{\boldsymbol{i}}\right)(\boldsymbol{i}=1$, 2 and 3) representing the internuclear distances of Helium atoms, $\rho$ is the vector with representing the distance between the center-of-mass of the molecule system 
Using the symmetrical system conditions, are given, in terms of internuclear distance, the hyperradius $(\rho)$ and hyperangles $(\Theta, \Phi)$ by:

$$
\begin{gathered}
\rho=\frac{\sqrt{\left(r_{1}^{2}+r_{2}^{2}+r_{3}^{2}\right)}}{3} \\
\cos (2 \Theta)=\frac{\left(-r_{1}^{2}+r_{2}^{2}\right) \sqrt{13 r_{1}^{4}+22 r_{1}^{2} r_{2}^{2}+13 r_{2}^{4}-12\left(r_{1}^{2}+r_{2}^{2}\right) r_{3}^{2}+3 r_{3}^{4}}}{\left(2\left(r_{1}^{2}+r_{2}^{2}\right)-r_{3}^{2}\right)\left(r_{1}^{2}+r_{2}^{2}+r_{3}^{2}\right)} \\
\cos (\Phi)=\frac{\left(r_{1}^{2}-r_{2}^{2}\right)}{\sqrt{\left(r_{1}^{2}-r_{2}^{2}\right)^{2}+3\left(-2\left(r_{1}^{2}+r_{2}^{2}\right)+r_{3}^{2}\right)^{2}}}
\end{gathered}
$$

and, conversely, the internuclear distances are given by:

$$
\begin{gathered}
r_{1}=\rho \sqrt{(3+3 \cos (2 \Theta) \cos (\Phi))} \\
r_{2}=\rho \sqrt{(3+1.5 \cos (2 \Theta)(\cos (\Phi)+\sqrt{3} \sin (\Phi)))} \\
r_{3}=\rho \sqrt{(3-1.5 \cos (2 \Theta)(\cos (\Phi)-\sqrt{3} \sin (\Phi)))}
\end{gathered}
$$

Using the above coordinates, the PES can functions multiplied by radial coefficients be expanded into a series of angular (expansion moments). ${ }^{25-27}$

$$
V(\rho ; \Theta, \Phi)=\sum_{l, m, n} v_{m, n}(\rho) F_{m, n}^{l}(\Theta, \Phi)
$$

where the $v_{m, n}(\rho)$ coefficients are the expansion moments depending on the $\rho$ coordinate and $F_{m, n}^{l}(\Theta, \Phi)$ are angular functions which can be written as the real Wigner $D$-functions, where the $D$-function is given $D_{m, n}^{l}(\Theta, \Phi, \gamma)=e^{-i m \Theta} d_{m, n}^{l}(\Phi) e^{-i n \gamma}(l=$ $0,1,2, \ldots ; m=n= \pm l) \quad$ and $d_{m, n}^{l}(\Theta) e^{-i n \gamma}$, were $d_{m, n}^{l}(\Theta)$ is tabulated function. ${ }^{27,28}$
The truncation of the set of basis functions to a certain value of the index $l$ depends on the number of fixed atommolecule configurations for which the potential energy is known as a function of $\rho$ from ab initio calculations. In terms of the Wigner $D$-functions that are complex-valued, the $F_{m, n}^{l}(\Theta, \Phi, \gamma)$ are found to be simple real-valued linear combinations:

$$
F_{m, n}^{l}(\Theta, \Phi, \gamma)=\sqrt{\frac{8 \pi^{2}}{2(2 l+1)}}\left(D_{m, n}^{l}(\Theta, \Phi, \gamma)+\epsilon D_{-m,-n}^{l}(\Theta, \Phi, \gamma)\right)
$$


Albernaz, A. F.; Barreto, P. R. P.

$$
F_{-m,-n}^{l}(\Theta, \Phi, \gamma)=i \sqrt{\frac{8 \pi^{2}}{2(2 l+1)}}\left(\epsilon D_{m, n}^{l}(\Theta, \Phi, \gamma)+D_{-m,-n}^{l}(\Theta, \Phi, \gamma)\right)
$$

where $\quad \epsilon=(-1)^{m-n}$. For

$l=0, F_{0,0}^{0}(\Theta, \Phi, \gamma)=D_{0,0}^{0}=d_{0,0}^{0}=1 \quad$ and

$l=1, d_{m, n}^{1}(\Theta)$ can be obtained from eqs. (4)

and (5) are listed in Table 1.

Truncation equation (3) at $l=0$ and 1 , consequently $m=n=0$ and $\pm 1, \quad$ and considering the $\gamma=0$, which is enough to represent a three body system, we have:

$$
\begin{aligned}
V(\rho, \Theta, \Phi)=\sqrt{2}\left\{v_{0,0}(\rho) d_{0,0}^{0}(4 \Phi)+v_{0,1}(\rho)\left[d_{0,0}^{1}(4 \Phi)+d_{0,1}^{1}(4 \Phi)\right]+\right. \\
\left.+v_{1,1}(\rho) \cos (6 \Theta)\left[d_{1,0}^{1}(4 \Phi)+d_{1,1}^{1}(4 \Phi)\right]\right\}
\end{aligned}
$$

Table 1. Real Hyperspherical Harmonics - $\boldsymbol{d}_{m, n}^{l}(\boldsymbol{\Theta}, \boldsymbol{\Phi}, \boldsymbol{\gamma})$ for $\boldsymbol{l}=\mathbf{1}$

\begin{tabular}{c|ccc}
\hline \hline$m / n$ & 1 & 0 & -1 \\
\hline \hline 1 & $\frac{1+\cos (6 \Phi)}{\sqrt{2}}(\cos (6 \Theta) \cos \gamma-\sin (6 \Theta) \sin \gamma)$ & $-\sin (6 \Phi) \cos (6 \Theta)$ & $\frac{1-\cos (6 \Phi)}{\sqrt{2}}(\cos (6 \Theta) \sin \gamma-\sin (6 \Theta) \cos \gamma)$ \\
0 & $\sin (6 \Phi) \cos \gamma$ & $\cos (6 \Phi)$ & $-\sin (6 \Phi) \sin \gamma$ \\
-1 & $\frac{1-\cos (6 \Phi)}{\sqrt{2}}(\cos (6 \Theta) \cos \gamma+\sin (6 \Theta) \sin \gamma)$ & $-\sin (6 \Theta) \sin (6 \Phi)$ & $\frac{1+\cos (6 \Phi)}{\sqrt{2}}(\sin (6 \Theta) \cos \gamma+\cos (6 \Theta) \sin \gamma)$ \\
\hline \hline
\end{tabular}

The eq. (6) shows that three not dependent radial functions are needed for $V$, thus we considered three configurations of the $\mathrm{He}_{3}$ complex: the linear disposition corresponding to $\Theta=\Phi=0$; the equilateral triangle $(\Theta=\pi / 4$ independent of the value of $\Phi)$; and a scalene triangle $(\Theta=\pi / 6$ and
$\Phi=7 \pi / 36$ ). The isosceles triangle configuration (an isosceles triangle corresponding to $\Theta=\pi / 6$ and $\Phi=\pi / 4$ ) was choose as a test configuration to verify the quality results of the method, see Table 2 for details.

Table 2. Definition of Leading Configurations, in terms of the $\Theta, \Phi$ and internuclear angles

\begin{tabular}{c|c|c|c|c}
\hline \multirow{2}{*}{ Configuration } & \multicolumn{2}{|c|}{$\begin{array}{c}\text { Hyperspherical } \\
\text { Coordinates }\end{array}$} & \multicolumn{2}{c}{ Internuclear Angles } \\
\cline { 2 - 4 } & $\Theta$ & $\Phi$ & \multicolumn{2}{|c}{} \\
\hline \hline Equilateral & $45 \circ$ & Ind & \multicolumn{2}{c}{$60 \circ$} \\
Linear & $0 \circ$ & $0 \circ$ & \multicolumn{2}{c}{$180 \circ$} \\
\hline Scalene & $30 \circ$ & $35 \circ$ & $63.71^{\circ}$ & 37.340 \\
\hline Isoceles & $30 \circ$ & $60 \circ$ & 71.570 & 36.870 \\
\hline \hline
\end{tabular}


The expansion moments are then obtained by a linear combination of the potential profiles calculated for the leading configurations. The moments $v_{m, n}(\rho)$ are related to the potentials of the leading configurations by:

$$
\begin{gathered}
V_{e q}=\frac{2 v_{0,0}-2 v_{0,1}}{\sqrt{2}} \\
V_{s c}=\frac{2 v_{0,0}+\left(\sqrt{\frac{3}{2}}-1\right) v_{0,1}}{\sqrt{2}} \\
V_{\text {lin }}=\frac{2 v_{0,0}+2 v_{0,1}+2 v_{1,1}}{\sqrt{2}}
\end{gathered}
$$

where, the indices $e q, \quad s c$ and $\operatorname{lin}$ above system of equations for $v_{0,0}, v_{0,1}$ and corresponding to equilateral, scalene and $v_{1,1}$, gives:

linear geometries, respectively. Solving the

$$
\begin{gathered}
v_{0,0}(\rho)=\frac{(\sqrt{3}-\sqrt{2}) V_{e q}(\rho)+2 \sqrt{2} V_{s c}(\rho)}{2+\sqrt{6}} \\
v_{0,1}(\rho)=\frac{2 \sqrt{2}\left(V_{e q}(\rho)-V_{s c}(\rho)\right)}{2+\sqrt{6}} \\
v_{1,1}(\rho)=\frac{(3 \sqrt{2}-\sqrt{3}) V_{e q}(\rho)-4 \sqrt{2} V_{s c}(\rho)+(\sqrt{2}+\sqrt{3}) V_{l i n}(\rho)}{2+\sqrt{6}}
\end{gathered}
$$

Therefore, by substituting eq. (8) into eq. is express in terms $V_{\text {lin }}, V_{e q}$ and $V_{s c}$ (6) the potential energy surface $(V(\rho, \Theta, \Phi))$ potentials, gives:

$$
\begin{gathered}
V(\rho, \Theta, \Phi)=\sqrt{2}\left\{\left(\frac{(\sqrt{3}-\sqrt{2}) V_{e q}(\rho)+2 \sqrt{2} V_{s c}(\rho)}{2+\sqrt{6}}\right)+\left(\frac{2 \sqrt{2}\left(V_{e q}(\rho)-V_{s c}(\rho)\right)}{2+\sqrt{6}}\right)\left[d_{0,0}^{1}(4 \Phi)+\right.\right. \\
\left.\left.d_{0,1}^{1}(4 \Phi)\right]+\left(\frac{(3 \sqrt{2}-\sqrt{3}) V_{e q}(\rho)-4 \sqrt{2} V_{s c}(\rho)+(\sqrt{2}+\sqrt{3}) V_{l i n}(\rho)}{2+\sqrt{6}}\right) \cos (6 \Theta)\left[d_{1,0}^{1}(4 \Phi)+d_{1,1}^{1}(4 \Phi)\right]\right\}
\end{gathered}
$$

The analytical form of the potential energy surfaces, for each of the leading configurations, are constructed by fitting the following fifth degree generalized Rydberg function ${ }^{26-28,30}$ into the ab initio points:

Rev. Virtual Quim. |Vol 8 | |No. 2| |338-355| 


$$
U(\rho)=D_{e} \sum_{i=1}^{5}\left(1+a_{i}\left(\rho-\rho_{e q}\right)^{i}\right) \exp \left[-a_{i}\left(\rho-\rho_{e q}\right)\right]+E_{r e f}
$$

where $D_{e}, a_{i}, \rho_{e q}$ and $E_{r e f}$ are parameters obtained by the fitting procedure.

In the discussion of the results, the energies of an isolated helium atom, the dimer, and the trimer are denoted as $E_{H e}$, $E_{\mathrm{He}_{2}}$ and $E_{\mathrm{He}_{3}}$, respectively. Differences in energies, which are the corresponding binding energies, are denoted

$$
\begin{gathered}
\Delta E_{\mathrm{He}_{2}}=E_{\mathrm{He}_{2}}-2 E_{\mathrm{He}} \\
\Delta E_{\mathrm{He}_{3}}=E_{\mathrm{He}_{3}}-3 E_{\mathrm{He}}
\end{gathered}
$$

The term $E_{\text {non-add }}$, the nonadditive part of the total energy, is denoted

$$
\Delta E_{\text {non-add }}\left(r_{1}, r_{2}, r_{3}\right)=\Delta E_{H e_{3}}-\Delta E_{H e_{2}} .
$$

Consequently, the construction of an interaction model to be used in a subsequent calculation consists in selecting proper functions representing the two-body $\left(E_{\mathrm{He}_{2}}\left(r_{\mathrm{He}-\mathrm{He}}\right)\right)$ and three-body $\left(\Delta E_{\mathrm{He}_{3}}\left(r_{1}, r_{2}, r_{3}\right)\right)$ potentials.

We have not considered the counterpoise correction, as suggested by Varandas et. al. what concluded that energies calculated with a cost-effective extrapolating basis set combined with extrapolated levels what include high corrections, as CBS, CCSD(T) and $\mathrm{FCl}$, as a promising route for accurate potentials, even when CP is not used; this may help to avoid correcting for BSSE, which presents formal difficulties when more than two fragments or more than one electronic state are involved. ${ }^{31}$

\section{Results and Discussion}

All the ab initio calculations were carried out by using the Molpro2010 program. ${ }^{32}$ The $\operatorname{CCSD}(\mathrm{T})$ and $\mathrm{MRCl}$ levels of theory were adopted in conjunction with the aug-cc-pVXZ
$(X=D, T, Q, 5,6) .^{32-35}$ Moreover, to assess the role of doubly augmented cc-pVQZ Basis, we tested the d-aug-cc-pVQZ. ${ }^{36}$ We will use short-hand notation $d-a Q Z$ for these base, and similarly aXZ ( $X=D, T, Q, 5$ and 6$)$ for the singly augmented ones.

We have computed the energies of 101 energies to different values of $R$ for the $\mathrm{He}$ dimer. A non linear least-squares procedure was used to obtain the values of the adjustable parameters that minimize the differences between the analytical energies obtained with the fifth degree generalized Rydberg function. The $D_{e}, a_{i}, R_{e q}, E_{r e f}$ adjustable parameters and $r m s$ error to $\mathrm{He}_{2}$ are listed in Table A1 of the Appendix.

The Table 3 show one resume of these results compared with experimental and/or theoretical data. We notice, in particular, that the best theoretical dimer interatomic potential result is $7.9905 \mathrm{~cm}^{-1}$ to $\mathrm{MRCl}$ at the distance $2.9631 \AA$ and $8.9019 \mathrm{~cm}^{-1}$ to $\operatorname{CCSD}(T)$ at the distance $2.9894 \AA$; both using the d-aug-cc-pVQZ basis set. In a corresponding calculation, using an exact Monte Carlo procedure, Szalewicz and Monkhorst obtained the value of $(7.6439 \pm 0.033) \mathrm{cm}^{-1}$ at the distance $5.60 a_{0}$ 
(2.9634 ̊̊). ${ }^{37}$ In the very recent work by Røeggen on the fcc and hcp structures of helium it was demonstrated that the EXRHF model yields a dimer interatomic potential equal to $7.5866 \mathrm{~cm}^{-1}$ at the distance $5.60 a_{0}$ when a practically complete basis set isadopted. ${ }^{38}$

Table 3. The energy and distance fitting of the He dimer

\begin{tabular}{l|c|c|c|c}
\hline \hline \multirow{2}{*}{ Basis Set } & \multicolumn{2}{|c|}{$\mathrm{E}^{\mathrm{He}_{2}}\left[\mathrm{~cm}^{-1}\right]$} & \multicolumn{2}{c}{$\mathrm{R}_{\mathrm{e}}[\AA]$} \\
\cline { 2 - 5 } & $\mathrm{MRCl}$ & $\mathrm{CCSD}(\mathrm{T})$ & $\mathrm{MRCl}$ & $\mathrm{CCSD}(\mathrm{T})$ \\
\hline $\mathrm{aDZ}$ & 8.7050 & 9.1897 & 3.0039 & 3.0158 \\
$\mathrm{aTZ}$ & 6.3466 & 7.0490 & 3.0097 & 3.0389 \\
$\mathrm{aQZ}$ & 6.0756 & 6.8941 & 2.9877 & 3.0161 \\
$\mathrm{~d}-\mathrm{aQZ}$ & 7.9905 & 8.9019 & 2.9631 & 2.9894 \\
$\mathrm{a} 5 Z$ & 6.2894 & 7.1538 & 2.9857 & 3.0164 \\
$\mathrm{a} 6 Z$ & 6.2990 & 7.2006 & 2.9799 & 3.0114 \\
\hline \multirow{4}{*}{ References } & \multicolumn{2}{|c|}{$7.6437 \pm 0.033)^{37}$} & & \\
& \multicolumn{2}{|c|}{$7.5866^{38}$} & \multicolumn{2}{|c}{$2.9634^{37-40}$} \\
& \multicolumn{2}{|c|}{$7.6106^{39, \mathrm{a}}$} & \multicolumn{2}{|c}{} \\
\hline
\end{tabular}

${ }^{a}$ Based on ab initio 78-MRCI with IO301 basis set calculations by Ref. 39.

${ }^{b}$ Obtained with $\operatorname{CCSD}(T) /[6 s, 5 p, 4 d, 3 f, 2 g, 1 h]$ level by Ref. 40 .

Our results to energies and distances are good agreement with Szalewicz and Monkhorst ${ }^{37}$ for the $d$-aQZ basis set to both levels. For distance our results are below $0.1 \%$ to both levels. For energy, discrepancies are below $5 \%$ to $\mathrm{MRCl}$ level and $16.5 \%$ to $\operatorname{CCSD}(T)$ level. In comparison to energy of the Bovenkamp and Duijneveldt, ${ }^{39}$ obtained with $78-\mathrm{MRCl}$ with 10301 basis set calculations, the discrepancy is $\sim 5 \%$ to MRCl level. While compared with results of Koppler and Noga, ${ }^{40}$ obtained with $\operatorname{CCSD}(T) /[6 s, 5 p, 4 d, 3 \quad f, 2 g, 1 h]$ level, the discrepancy is $\sim 20 \%$ to $\operatorname{CCSD}(\mathrm{T})$ level.

It is well-known that the $\mathrm{MRCl}$ methods allow one to reproduce the wave function in the valence region (describing static and nondynamic correlation effects) more reliably in general than the single-reference coupledclusters ones in complicated cases. It is not less known that the dynamic correlation effects (with explicit treatment of outer core shells, etc.) are much better described by the coupled-clusters approaches. This explained the difference between $\mathrm{MRCl}$ and $\operatorname{CCSD}(\mathrm{T})$ results obtained in this work.

\subsection{Potential Energy Surface Fit}

We have computed the energies of 101 single potential energy points on the surface to different values of $\rho$ for each configuration, and then we have fitted the energies vs $\rho$ by means of a nonlinear leastsquare procedure. A nonlinear least-squares procedure was used to obtain the values of the adjustable parameters that minimize the differences between the analytical energies obtained with the function (equation 10) and the MCRI and $\operatorname{CCSD}(T)$ to several basis set data. The $D_{e}, a_{i}, \rho_{e q}, E_{r e f}$ adjustable parameters and $r m s$ error to the $\mathrm{MRCl}$ and $\operatorname{CCSD}(T)$ potentials are listed in Table $A 2$ of the Appendix.

The smallest difference between the distance corresponding to the minimum energy in the leading configuration when 
comparing the $\operatorname{CCSD}(T)$ and $\mathrm{MRCl}$ results is found for the equilateral configuration at aug-cc-pVDZ (aDZ) level, amounting ca $0.0098 \AA$, and the largest is obtained for the linear configuration at aug-cc-pV6Z level, ca $0.0327 \AA$ becoming $0.0333 \AA$ for the test configuration.

As to the interaction energies, the largest difference is encountered for the d-aug-ccpVQZ basis set, in correspondence of the equilateral triangle configuration, 3.5254 $\mathrm{cm}^{-1}$ and the smallest one is for the scalene triangle at aug-cc-pVDZ, $0.8334 \mathrm{~cm}^{-1}$. For the test configuration the difference is 0.8050 $\mathrm{cm}^{-1}$.

Since the adopted basis set in this work yields a dimer potential which is in $r m s$ by less than 0.001 (see Table A1) to $\mathrm{MRCl} / \mathrm{d}$ $\mathrm{aQZ}$, it should be accurate enough to describe the changes in the double pair correction terms due to the presence of a third subsystem, i.e., its contribution to the three-body potential.

Table 4. Hyperradius $(\rho)$, internuclear distance $\left(\boldsymbol{R}_{\boldsymbol{e}}\right)$, total interaction energy $\left(\boldsymbol{E}_{\boldsymbol{H}_{3}}\right)$ and three-body nonadditive $\left(\Delta \boldsymbol{E}_{\mathrm{He}_{3}}\right)$ contributions term obtained, from the PES fit, to equilateral configuration from the Helium trimer to $\mathrm{MRCl}$ and $\operatorname{CCSD}(\mathrm{T})$ levels and several basis sets

\begin{tabular}{|c|c|c|c|c|c|c|c|c|}
\hline \multirow{2}{*}{$\begin{array}{l}\text { Basis } \\
\text { Set }\end{array}$} & \multicolumn{2}{|c|}{$\rho[\AA ̊]$} & \multicolumn{2}{|c|}{$\begin{array}{c}R_{e}[\AA] \\
\left(r_{1}=r_{2}=r_{3}\right)\end{array}$} & \multicolumn{2}{|c|}{$E_{\mathrm{He}_{3}}\left[\mathrm{~cm}^{-1}\right]$} & \multicolumn{2}{|c|}{$\Delta E_{\mathrm{He}_{3}}\left[\mathrm{~cm}^{-1}\right]$} \\
\hline & $\mathrm{MRCl}$ & $\operatorname{CCSD}(T)$ & $\mathrm{MRCl}$ & $\operatorname{CCSD}(T)$ & $\mathrm{MRCl}$ & $\operatorname{cCSD}(T)$ & $\mathrm{MRCl}$ & $\operatorname{CCSD}(T)$ \\
\hline $\mathrm{aDZ}$ & 1.7429 & 1.7331 & 3.0187 & 3.0018 & 24.8815 & 26.8902 & 1.2335 & -0.6791 \\
\hline aTZ & 1.7540 & 1.7325 & 3.0381 & 3.0008 & 18.0840 & 20.9573 & 0.9559 & -0.1897 \\
\hline $\mathrm{aQZ}$ & 1.7440 & 1.7231 & 3.0208 & 2.9845 & 18.0180 & 21.2052 & 0.2089 & 0.5228 \\
\hline$d-a Q z$ & 1.7289 & 1.7080 & 2.9945 & 2.9600 & 22.5988 & 26.1242 & $\begin{array}{c}- \\
1.3726\end{array}$ & -0.5814 \\
\hline a5Z & 1.7430 & 1.7202 & 3.0190 & 2.9795 & 18.1611 & 21.5255 & 0.7070 & 0.0640 \\
\hline a6z & 1.7410 & 1.7176 & 3.0155 & 2.9750 & 18.2744 & 21.7633 & 0.6227 & 0.1614 \\
\hline \multicolumn{3}{|c|}{$\operatorname{CCSDT}(\mathrm{Q}) / \mathrm{d}-\mathrm{aQZ} \mathrm{Z}^{17}$} & & & \multicolumn{2}{|c|}{23.07} & \multicolumn{2}{|c|}{-0.0614} \\
\hline \multicolumn{3}{|c|}{ DMC calculations ${ }^{20}$} & & & & & \multicolumn{2}{|c|}{-1.26} \\
\hline \multicolumn{3}{|c|}{$(\mathrm{MRCl}+Q) /[5 s, 4 p, 3 \mathrm{~d}, 2 \mathrm{f}]^{22}$} & & & & & \multicolumn{2}{|c|}{0.1756} \\
\hline \multicolumn{3}{|c|}{ EXRHF/[19s,7p,6d, $5 f, 4 g, 2 h]^{37}$} & & & & & \multicolumn{2}{|c|}{-0.0555} \\
\hline \multicolumn{3}{|c|}{$\operatorname{CCSD}(T) /[7 s, 5 p, 3 d, 2 f]^{42}$} & & & & & \multicolumn{2}{|c|}{-0.0694} \\
\hline \multicolumn{3}{|c|}{ DMC calculations ${ }^{43}$} & & & \multicolumn{2}{|c|}{22.9} & \multicolumn{2}{|c|}{-0.0872} \\
\hline \multicolumn{3}{|c|}{ EXRHF/[19s, $7 p, 6 d, 5 f, 4 g, 2 h]^{44}$} & & & \multicolumn{2}{|c|}{$14.94 \pm 1.32$} & \multicolumn{2}{|c|}{$0.487 \pm 1.5$} \\
\hline
\end{tabular}

Table 4 contains the main calculated results of this work to $\mathrm{MRCl}$ and $\operatorname{CCSD}(\mathrm{T})$ levels using several basis set for the equilibrium equilateral triangle. The hyperradius is $1.7289 \AA$, with an total interaction energy of $22.5988 \mathrm{~cm}^{-1}$ and the equilibrium internuclear distance obtained is $2.9945 \AA$ for the $\mathrm{MRCl} / \mathrm{d}$-aQZ level; while to $\operatorname{CCSD}(\mathrm{T}) / \mathrm{d}$-aQZ the hyperradius is 1.7080 $\AA$, with an total interaction energy of 26.1242 $\mathrm{cm}^{-1}$ and the equilibrium internuclear distance obtained is $2.9600 \AA$. 
We present also some results of the most recent calculations of the three-body potential of the helium trimer. Among these calculations, the calculation of Cohen and Murrell is the odd one. ${ }^{22}$ As pointed out by Lotrich and Szalewicz, ${ }^{38}$ there might be two reasons for this deviation. First, the adopted multireference configuration interaction $\mathrm{MRCl}$ method, combined with a size consistent correctionfor unlinked clusters $\mathrm{MRCl}+\mathrm{Q}$, is not fully size consistent. Second, in a supermolecule approach it is of paramount importance to correct for the BSSE. Cohen and Murrell did not specify if this is done. If they did not, this might be the main reason for the discrepancy.

Our accurate energy $\mathrm{MRCl} / \mathrm{d}$-aQZ for the trimer $E_{\mathrm{He}_{3}}=22.5988 \mathrm{~cm}^{-1}$ is in excellent agreement with the Lewerenz ${ }^{44}$ value, $E_{\mathrm{He}_{3}}=22.9 \mathrm{~cm}^{-1}$, with DMC calculations and Cencek et. al. ${ }^{18}$ value, $E_{\mathrm{He}_{3}}=23.01 \mathrm{~cm}^{-1}$, carried out using the $\operatorname{CCSDT}(\mathrm{Q}) / \mathrm{d}$-aQZ level. Our result of the $\Delta E_{\mathrm{He}_{3}}$ at $\mathrm{MRCl} / \mathrm{d}$-aQZ basis set is $\quad-1.3726 \mathrm{~cm}^{-1}$ using MRCl. This result is good agreement with the $-1.26 \mathrm{~cm}^{-1}$ obtained used DMC calculations of the Blume and Greene. ${ }^{20}$
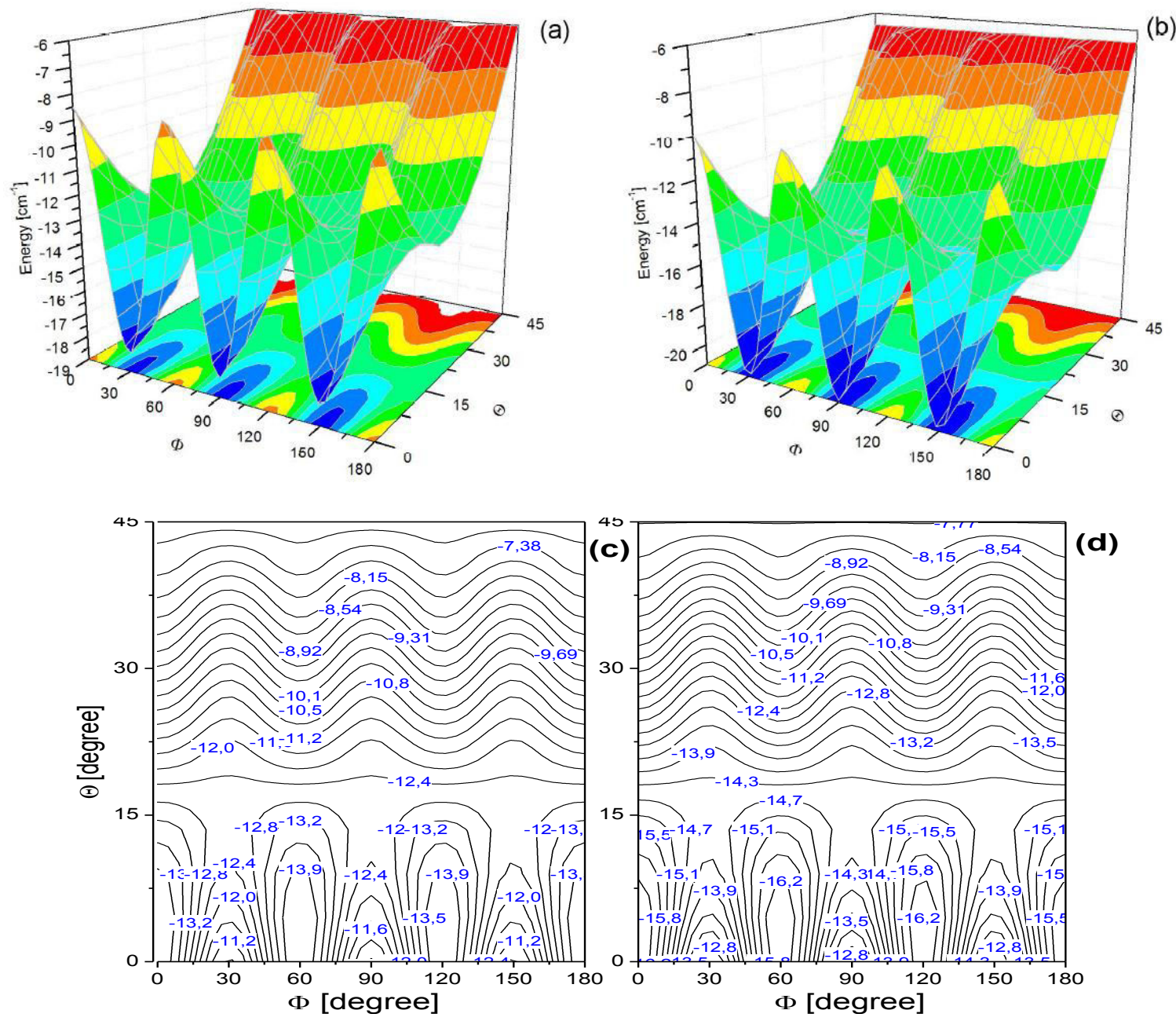

Figure 2. Illustration of the potential energy surface as a function of the hyperangles $\Theta$ and $\Phi$, using the isotropic distance $\rho$ to d-aug-cc-pVQZ; (a) for $\mathrm{MRCl}(\rho=1.7289 \AA$ ) and (b) for $\operatorname{CCSD}(T)(\rho=1.7280 \AA)$. In the (c) and (d) figures we show two-dimensional contours as a function of the hyperangles $\Theta$ and $\Phi$. In this contours the effect of particle permutations on the angle $\Phi$ can be clearly seen through the isoenergetic curves (c) and (d) 
Figure 2 shows a surface plot of the $\mathrm{He}$ trimer potential used in the present study. For a fixed hyperradius $\rho, 1.7289$ and 1.7280 $\AA$ ( $\mathrm{MRCl}$ - Figure 2(a) and CCSD(T) - Figure 2(b), respectively) to d-aug-cc-pVQZ basis set, as a function of the hyperangles $\Theta$ and $\Phi$. We show the angular range $\Theta[0, \pi / 4]$ and $\Phi[0, \pi]$.

The two-dimensional contour (Figures 2(c) and 2(d)) demonstrated the effect of particle permutations on the angle $\Phi$. Due to the presence of three indistinguishable particles, $V(\rho, \Theta, \Phi)$ is invariant under translation by $\pi / 3$ in the $\Phi$-direction. Note that the twobody coalescent points with $r_{12}=0, r_{23}=0$, and $r_{31}=0$ correspond to $(\Theta, \Phi)=(\pi / 4, \pi / 6)$, $(\pi / 4,4 \pi / 6)$, and $(\pi / 4, \pi)$, respectively.

The symmetry lines of the potential surface $\Phi=n \pi / 6$, where $n=1-6$ can easily be identified. The contours plot of this figure is similar to that of Suno and Esry ${ }^{2}$ for $\mathrm{He}_{3}$ and of Blume et. al. for $\mathrm{Ne}_{3}{ }^{23}$ In both cases, the author show the contours plot at distance of $7.93766 \AA$, while we use the distance for the isotropic term.

The rms for the leading and test configurations present a minimum for the $d$ aug-cc-pVQZ basis set and varies from $0.000644 \mathrm{~cm}^{-1}$ for the equilateral triangle. This strongly indicates that the most reliable results pertain to the d-aug-cc-pvQZ basis set, therefore all the data discussed in the following are referred to the above basis set.

In Figure 3, we illustrate of the potential interaction (equation 6) of the $\mathrm{He}_{3}$ system as a function of the hyperradius distance. This figure compares the ab initio $(\mathrm{MRCl}$ and $\operatorname{CCSD}(T))$ and the fitted results for the leading (Figure 3(a)) and test (Figure 3(b)) configurations, where the ab initio points are compared with the results obtained by the mode (equation 9). Although the isosceles configuration not be part of the model, it can play very well the $a b$ initio points.
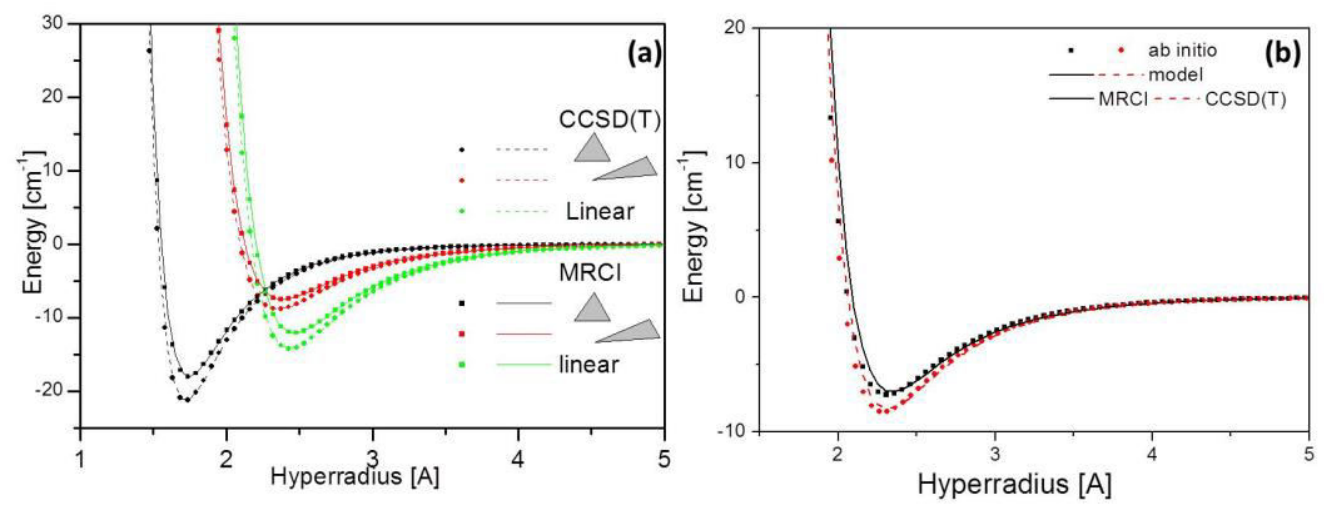

Figure 3. Interaction energies as a function of the hyperradius for the equilateral, scalene, linear (figure 3(a)) configurations. Circles and squares symbols represent the ab initio points calculated to $\mathrm{MRCl}$ and $\operatorname{CCSD}(\mathrm{T})$ levels using the d-aug-cc-pVQZ base set, and solid and dash lines are from Rydberg fitting. The figure 3(b), test configuration (the isoceles triangle with $\Theta=$ $\pi / 6$ and $\Phi=\pi / 4$ ), was obtained by the model (eq. 9)

The $r m s$ between the computed and the fitted values ranges in $(6-43) \times 10^{-4} \mathrm{~cm}^{-1}$ to $\mathrm{MRCl}$ and $\operatorname{CCSD}(\mathrm{T})$ for all configurations (see Table A2), thus validating the quality of the fit. The d-aug-cc-pVQZ basis set presents the minimum equilibrium distance and the maximum interaction energy.

Figure $3(b)$ compares the ab initio points with results obtained according the model (equation 9), for the test configuration (see Table 2 for details). The $r m s$ among the 
$\mathrm{MRCl}$ data is $2.71403 \mathrm{~cm}^{-1}$ while according the fitting procedure it is $0.000644 \mathrm{~cm}^{-1}$. For the results in $\operatorname{CCSD}(\mathrm{T})$ the error is 4.51408 versus $0.000644 \mathrm{~cm}^{-1}$. The errors are large in the small hyperradius than in the region of bigger hyperradius.
Figure 4 compares the isotropic $\left(v_{00}\right)$ and anisotropic $\left(v_{01}\right.$ and $\left.v_{11}\right)$ terms at $\mathrm{MRCl}$ and $\operatorname{CCSD}(T)$. It has to be noted that the isotropic term constitutes very important information because it can be obtained by experimental determinations and can be used to compare different systems.

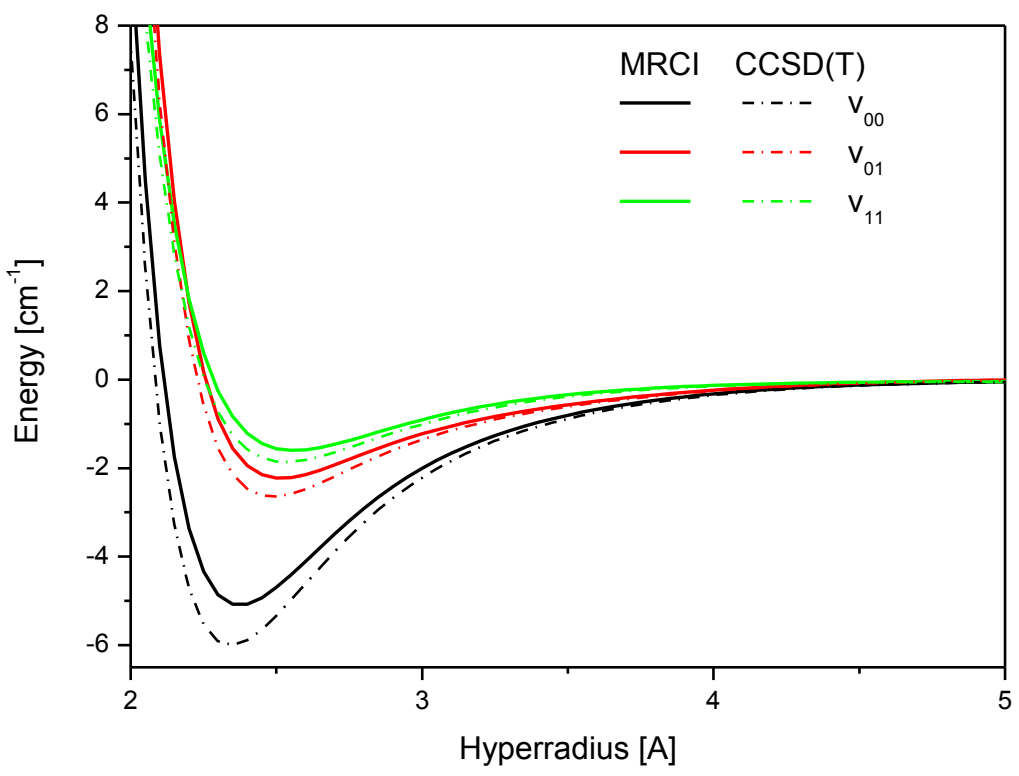

Figure 4. Energy dependence as a function of the hyperradius for the isotropic and anisotropic moments of the hyperspherical expansion

The projection of full potential energy surface in $x y$-plane, generated properly freezing the angles $\Theta$ or $\Phi$, is showed in Figure 5. These graphs have been obtained by using the full potential energy surface generated by the hyperspherical harmonics expansion, which produce a smooth interpolation among the curves corresponding to the three leading configurations that we have considered in this paper.
These figure show the projection of $\Phi$ with fixed $\Theta$ (a) $\Theta=0$ or (b) $\Theta=\pi / 4$. It is clear the period of the $\Phi$ angle of $\pi / 3$ in figure (a), but in figure 2 , as $\Theta=\pi / 4$ the $\Phi$ angle is undetermined, as showed in table 2 , (c) shows the projection of $\Theta$ with $\Phi=0$ and (d) with $\Phi=\pi / 3$, in both part (c) and (d) are clear the period of $\pi / 4$ for the $\Theta$ hyperangle. 

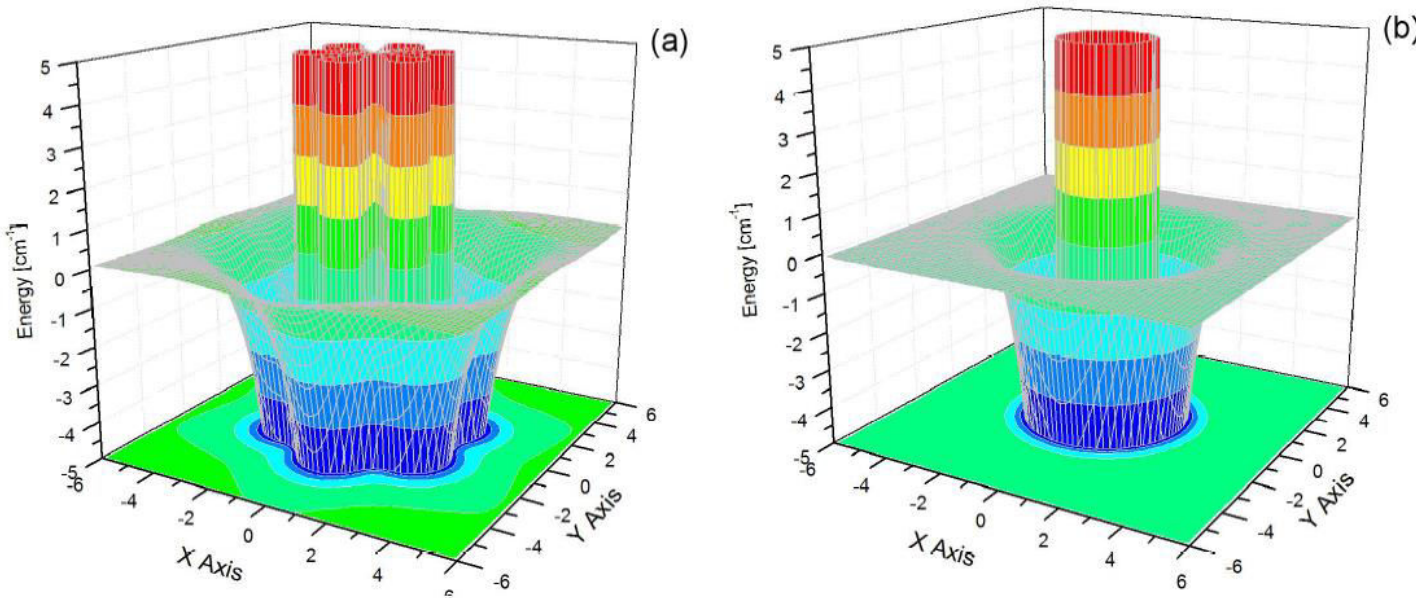

(b)
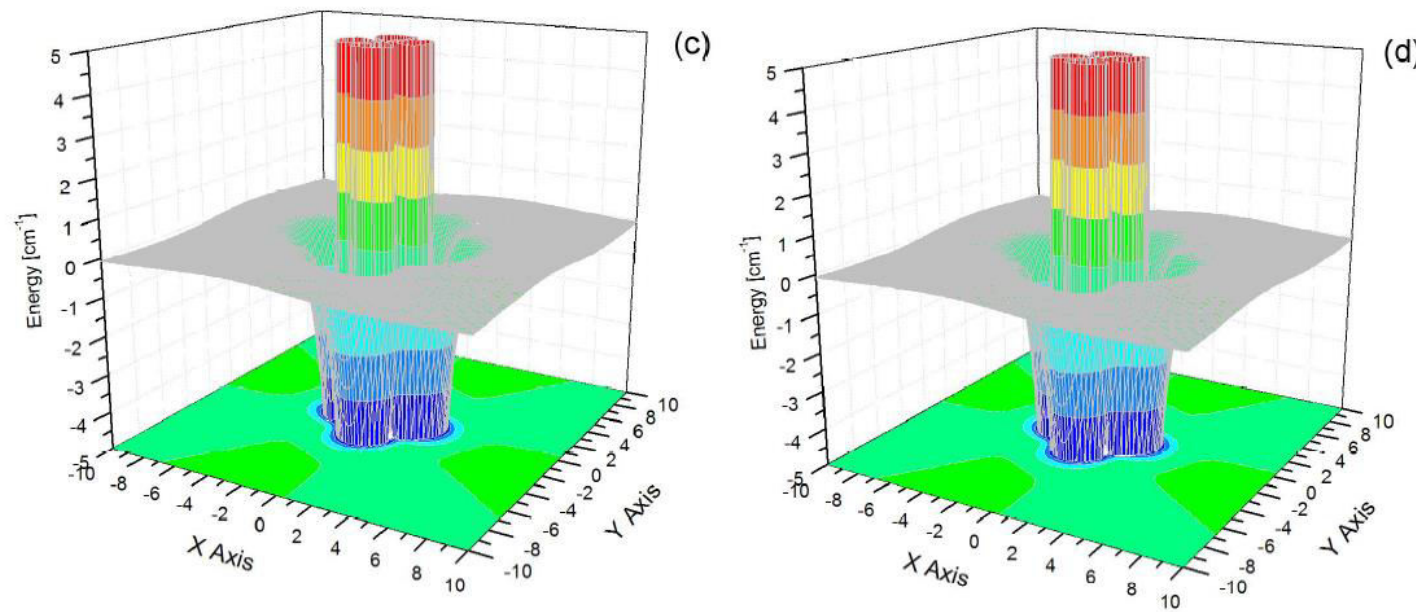

(d)

Figure 5. View of the potential energy surface for the interaction of $\mathrm{He}_{3}$ as $\Theta$ and $\Phi$, using the isotropic distance, $\rho=1.7289 \AA$, and $\mathrm{MRCl} / \mathrm{d}$-aug-cc-pVQZ. In (a) $\Phi$ varies in the $x y$ plane, with $\Theta=0$, (b) $\Phi$ varies in the $x y$ plane, with $\Theta=\pi / 4$, (c) $\Theta$ varies in the $x y$ plane, with $\Phi=0$, (d) $\Theta$ varies in the $x y$ plane, with $\Phi=\pi / 3$

\section{Conclusions}

We have used $\mathrm{MRCl}$ and $\operatorname{CCSD}(\mathrm{T})$ methods and several basis sets to compute the threebody nonadditive contribution to the helium trimer interaction energy and represented through a hyperspherical harmonic. To determine the expansion moments, we chose a three significant (leading) configurations, thought to be representative also on account of the symmetries of the systems. This has allowed us to build up an interaction potential expansion potentially useful for dynamical studies by classical or quantum mechanics.
The hyperspherical expansion appears to be a powerful tool: it allows implementation of symmetries and of further information coming from introduction of additional configurations. Interpretation of experimental molecular beam scattering studies can also be assisted by these investigations.

We have proposed a very simple, analytical potential energy surface for the $\mathrm{He}_{3}$ system, using the symmetric, mass unscaled hyperspherical coordinates. The trend obtained by others authors for $\mathrm{He}$ trimer and similar systems, where in $\mathrm{Ne}_{3}$ and $\mathrm{Ar}_{3}$, are well reproduced here. The $\mathrm{MRCl}$ and $\operatorname{CCSD}(T)$ potentials turned out to be very similar, give essentially the same results. The 
uncertainties of the nonadditive helium trimer potential using d-aug-cc-pVQZ basis sets and from fitting are about $0.004 \mathrm{~cm}^{-1}$ to the trimer minimum. The $\mathrm{MRCl} / \mathrm{d}$-aug-ccpVQZ level showed is more than adequate to study this system.

In conclusion, three-body potential for the ground state of the helium trimer is determined by an extensive calculation presented so far. Based on our error analysis and comparisons with others authors what different methods to the Helium trimer potential energy surface, we consider also these calculations to be the most accurate ones. The analytic functions for the threebody potential yield an effective and simple representation of the potential.

\section{Acknowledgments}

The authors are grateful to the Fundação de Amparo de Pesquisa do Estado de São Paulo (FAPESP) and Conselho Nacional de Desenvolvimento Científico e Tecnológico (CNPq) for the support.

\section{Appendix}

Table A1. Two-body analytic function to helium dimer obtained to $\mathrm{MRCl}$ and $\mathrm{CCSD}(\mathrm{T})$ levels and several basis sets

\begin{tabular}{|c|c|c|c|c|c|c|c|c|c|}
\hline \multirow{2}{*}{$\begin{array}{l}\text { Basis } \\
\text { Set }\end{array}$} & \multicolumn{9}{|c|}{$\mathrm{MRCl}$} \\
\hline & $a_{1}\left[\AA^{-1}\right]$ & $\mathrm{a}_{2}\left[\AA^{-2}\right]$ & $a_{3}\left[\AA^{-3}\right]$ & $a_{4}\left[\AA^{-4}\right]$ & $a_{5}\left[\AA^{-5}\right]$ & $\begin{array}{c}\mathrm{E}_{\mathrm{ref}} \\
{\left[\mathrm{cm}^{-1}\right]}\end{array}$ & $\begin{array}{c}\mathrm{D}_{\mathrm{e}} \\
{\left[\mathrm{cm}^{-1}\right]}\end{array}$ & $\mathrm{R}_{\mathrm{eq}}[\AA]$ & rms \\
\hline $\mathrm{aDZ}$ & 3.415787 & 1.259258 & 0.55028 & 0.857928 & 0.687064 & 0.17462 & 8.7050 & 3.0158 & 0.001147 \\
\hline aTZ & 2.055895 & -1.36529 & 2.247367 & -1.51887 & 0.403654 & 0.380208 & 6.3466 & 3.0389 & 0.002243 \\
\hline $\mathrm{aQZ}$ & 3.558893 & 1.85153 & 1.7681 & 1.321458 & 0.536468 & 0.077378 & 6.0756 & 3.0161 & 0.000173 \\
\hline$d-a Q Z$ & 2.758663 & -0.27441 & 1.110964 & 0.215113 & 0.289419 & 0.3645 & 7.9905 & 2.9894 & 0.000401 \\
\hline a5z & 2.569015 & -0.94126 & 1.30008 & -0.32576 & 0.184523 & 0.230077 & 6.2894 & 3.0164 & 0.000113 \\
\hline$a 6 z$ & 2.53998 & -1.07302 & 1.369963 & -0.40424 & 0.152782 & 0.183669 & 6.2990 & 3.0114 & $1.44 \mathrm{E}-06$ \\
\hline \multicolumn{10}{|c|}{$\operatorname{CCSD}(T)$} \\
\hline $\mathrm{aDZ}$ & 3.414403 & 1.274788 & 0.550779 & 0.838421 & 0.686003 & 0.179354 & 9.1897 & 3.0039 & 0.00113 \\
\hline aTZ & 2.063261 & -1.47647 & 2.303935 & -1.4938 & 0.379605 & 0.366437 & 7.0490 & 3.0097 & 0.002256 \\
\hline $\mathrm{aQZ}$ & 3.546051 & 1.783883 & 1.669134 & 1.250678 & 0.531804 & 0.082066 & 6.8941 & 2.9877 & 0.000171 \\
\hline $\mathrm{d}-\mathrm{aQZ}$ & 2.759573 & -0.30169 & 1.076766 & 0.18071 & 0.281098 & 0.373283 & 8.9019 & 2.9631 & 0.00041 \\
\hline a5z & 2.570582 & -0.96851 & 1.297542 & -0.32951 & 0.175589 & 0.239808 & 7.1538 & 2.9857 & 0.00011 \\
\hline a6z & 2.535884 & -1.11604 & 1.375317 & -0.40688 & 0.145733 & 0.193097 & 7.2006 & 2.9799 & 1.69E-06 \\
\hline
\end{tabular}


Table A2. Three-body analytic function (eq. (11)) for the leading configurations obtained to $\mathrm{MRCl}$ and $\operatorname{CCSD}(\mathrm{T})$ levels and several basis sets

\begin{tabular}{|c|c|c|c|c|c|c|c|c|c|c|}
\hline \multirow{2}{*}{ Basis Set } & \multirow{2}{*}{ Configurations } & \multicolumn{9}{|c|}{$\mathrm{MRCl}$} \\
\hline & & $a_{1}\left[\AA^{-1}\right]$ & $a_{2}\left[\AA^{-2}\right]$ & $a_{3}\left[\AA^{-3}\right]$ & $a_{4}\left[\AA^{-4}\right]$ & $a_{5}\left[\AA^{-5}\right]$ & $\mathrm{E}_{\mathrm{ref}}\left[\mathrm{cm}^{-1}\right]$ & $\mathrm{D}_{\mathrm{e}}\left[\mathrm{cm}^{-1}\right]$ & $\rho_{\text {eq }}[\AA]$ & $\mathrm{rms}$ \\
\hline \multirow[t]{3}{*}{$\mathrm{aDZ}$} & Equilateral & 5.670953 & 2.390386 & 1.960427 & 6.50082 & 8.629325 & -0.0533 & 24.881 & 1.7429 & 0.010615 \\
\hline & Scalene & 3.933895 & 0.910421 & 0.583547 & 0.918886 & 1.348534 & 0.0197 & 10.297 & 2.3898 & 0.003098 \\
\hline & Linear & 4.141615 & 1.747257 & 0.844911 & 1.670518 & 1.716155 & 0.0100 & 17.601 & 2.4615 & 0.004839 \\
\hline \multirow[t]{3}{*}{ aTZ } & Equilateral & 3.654171 & -4.26685 & 11.17461 & -10.9549 & 4.047226 & 0.0772 & 18.084 & 1.7540 & 0.020626 \\
\hline & Scalene & 2.578739 & -2.41127 & 4.685046 & -3.53893 & 1.118343 & 0.3196 & 7.993 & 2.3889 & 0.001959 \\
\hline & Linear & 2.506939 & -1.9741 & 4.174734 & -3.30061 & 1.110273 & 0.7327 & 12.969 & 2.4814 & 0.007901 \\
\hline \multirow[t]{3}{*}{ aQZ } & Equilateral & 4.931535 & -0.83734 & 5.954968 & 2.079468 & 1.792079 & -0.0537 & 18.018 & 1.7440 & 0.003696 \\
\hline & Scalene & 3.974911 & 0.991242 & 2.321968 & 1.490864 & 0.835723 & -0.0156 & 7.478 & 2.3849 & 0.000348 \\
\hline & Linear & 4.073514 & 1.65558 & 2.568822 & 2.02979 & 1.045606 & -0.0326 & 12.039 & 2.4668 & 0.001151 \\
\hline \multirow[t]{3}{*}{ d-aQZ } & Equilateral & 5.131096 & 0.925939 & 6.06384 & 4.931025 & 4.069759 & -0.0593 & 22.599 & 1.7289 & 0.004334 \\
\hline & Scalene & 3.610234 & -0.06035 & 1.684517 & 0.598157 & 0.930568 & 0.0476 & 10.032 & 2.3552 & 0.001039 \\
\hline & Linear & 3.654758 & 0.404937 & 2.092028 & 1.049145 & 0.843774 & 0.0804 & 15.494 & 2.4392 & 0.002013 \\
\hline \multirow[t]{3}{*}{ a5Z } & Equilateral & 4.228244 & -3.80604 & 7.398114 & -3.885 & 2.120015 & -0.0168 & 18.161 & 1.7430 & 0.000746 \\
\hline & Scalene & 3.333332 & -1.12986 & 2.295152 & -0.5349 & 0.478334 & 0.0218 & 7.527 & 2.3851 & $6.84 \mathrm{E}-05$ \\
\hline & Linear & 3.226953 & -1.19952 & 2.297333 & -0.59601 & 0.424293 & 0.0565 & 12.175 & 2.4666 & 0.00041 \\
\hline \multirow[t]{3}{*}{$\mathrm{a} 6 \mathrm{Z}$} & Equilateral & 4.118929 & -4.30912 & 8.000636 & -4.9618 & 2.310861 & -0.0101 & 18.274 & 1.7410 & $6.64 \mathrm{E}-05$ \\
\hline & Scalene & 3.243004 & -1.45174 & 2.505748 & -0.82469 & 0.452678 & 0.0225 & 7.556 & 2.3820 & 3.73E-06 \\
\hline & Linear & 3.146586 & -1.50271 & 2.460465 & -0.84125 & 0.414186 & 0.0577 & 12.261 & 2.4632 & 5.90E-06 \\
\hline & & \multicolumn{9}{|c|}{$\operatorname{CCSD}(T)$} \\
\hline \multirow[t]{3}{*}{ aDZ } & Equilateral & 5.655238 & 2.395923 & 1.958542 & 6.282626 & 8.562892 & -0.0595 & 26.890 & 1.7331 & 0.010583 \\
\hline & Scalene & 3.935259 & 0.950148 & 0.622091 & 0.896162 & 1.34246 & 0.0179 & 11.131 & 2.3754 & 0.002969 \\
\hline & Linear & 4.136003 & 1.76724 & 0.862102 & 1.633511 & 1.717742 & 0.0054 & 18.920 & 2.4484 & 0.004696 \\
\hline \multirow[t]{3}{*}{ aTZ } & Equilateral & 3.658618 & -4.5929 & 11.3192 & -10.6032 & 3.807974 & 0.0759 & 20.957 & 1.7325 & 0.020697 \\
\hline & Scalene & 2.58046 & -2.60883 & 4.773108 & -3.45783 & 1.050971 & 0.3247 & 9.223 & 2.3597 & 0.001989 \\
\hline & Linear & 2.510863 & -2.1917 & 4.302849 & -3.24909 & 1.045385 & 0.7344 & 14.892 & 2.4510 & 0.008017 \\
\hline \multirow[t]{3}{*}{$\mathrm{aQZ}$} & Equilateral & 4.606487 & -2.36907 & 6.274802 & -0.30339 & 1.318736 & -0.0477 & 21.205 & 1.7231 & 0.003824 \\
\hline & Scalene & 3.937203 & 0.823851 & 2.176859 & 1.301218 & 0.794199 & -0.0167 & 8.811 & 2.3554 & 0.000356 \\
\hline & Linear & 4.028938 & 1.451091 & 2.354986 & 1.781898 & 0.983421 & -0.0345 & 14.171 & 2.4374 & 0.001216 \\
\hline \multirow[t]{3}{*}{$d-a Q Z$} & Equilateral & 5.098626 & 0.645625 & 5.671055 & 4.309398 & 3.875399 & -0.0646 & 26.124 & 1.7089 & 0.004358 \\
\hline & Scalene & 3.608028 & -0.0824 & 1.63236 & 0.495209 & 0.905512 & 0.0479 & 11.530 & 2.3287 & 0.001022 \\
\hline & Linear & 3.64486 & 0.320311 & 1.988101 & 0.921185 & 0.816067 & 0.0795 & 17.888 & 2.4117 & 0.001956 \\
\hline \multirow[t]{3}{*}{ a5Z } & Equilateral & 4.207787 & -3.97902 & 7.430486 & -3.94956 & 2.053953 & -0.0174 & 21.526 & 1.7202 & 0.000746 \\
\hline & Scalene & 3.322466 & -1.2089 & 2.300483 & -0.57125 & 0.463306 & 0.0238 & 8.929 & 2.3531 & 6.61E-05 \\
\hline & Linear & 3.214423 & -1.28558 & 2.305526 & -0.62997 & 0.411718 & 0.0616 & 14.420 & 2.4346 & 0.000408 \\
\hline \multirow[t]{3}{*}{ a6Z } & Equilateral & 4.101965 & -4.48049 & 8.038834 & -4.93787 & 2.210977 & -0.0110 & 21.763 & 1.7176 & 7.32E-05 \\
\hline & Scalene & 3.229211 & -1.54908 & 2.521989 & -0.85079 & 0.439513 & 0.0250 & 9.012 & 2.3492 & 4.52E-06 \\
\hline & linear & 3.133871 & -1.59372 & 2.476261 & -0.85986 & 0.399194 & 0.06223 & 14.593 & 2.4305 & $6.80 \mathrm{E}-06$ \\
\hline
\end{tabular}

\section{References}

${ }^{1}$ Bressanini, D.; Morosi, G. Stability of ${ }^{3} \mathrm{He}_{2}{ }^{4} \mathrm{He}_{\mathrm{N}}$ and ${ }^{3} \mathrm{He}_{3}{ }^{4} \mathrm{He}_{\mathrm{N}} L=0$ Clusters.

Physical Review Letters 2003, 90, 133401. [CrossRef]
2 Suno, H.; Esry, B. D. Adiabatic hyperspherical study of triatomic helium systems. Physical Review A 2008, 78, 062701. [CrossRef]

${ }^{3}$ Lohr, L. L.; Blinder, S. M. Semiempirical hyperspherical model for ${ }^{4} \mathrm{He}_{\mathrm{N}}$ clusters. 
International Journal of Quantum Chemistry 2006, 106, 981. [CrossRef]

${ }^{4}$ Efimov, V. Energy levels arising from resonant two-body forces in a three-body system. Physical Letters B 1970, 33B, 563. [CrossRef]

${ }^{5}$ Efimov, V. Energy levels of three resonantly interacting particles. Nuclear Physics 1973, 210, 157. [CrossRef]

${ }^{6}$ Hegerfeldt, G. C.; Köhler, T. How to Study the Elusive Efimov State of the ${ }^{4} \mathrm{He}_{3}$ Molecule through a New Atom-Optical State-Selection Technique. Physical Review Letters 2000, 84, 3215. [CrossRef]

${ }^{7}$ González-Lezana, T.; Rubayo-Soneira, J.; Miret-Artés, S.; Gianturco, F. A.; DelgadoBarrio, G.; Villarreal, P. Efimov States for ${ }^{4}$ He Trimers? Physical Review Letters 1999, 82, 1648. [CrossRef]

${ }^{8}$ Aquilanti, V.; Cavalli, S.; Grossi, G.; Anderson, R. W. Representation in hyperspherical and related coordinates of the potential-energy surface for triatomic reactions. Journal of the Chemical Society, Faraday Transactions 1990, 86, 1681. [CrossRef]

${ }^{9}$ Aquilanti, V.; Cavalli, S.; de Fazio, D. Hyperquantization algorithm. I. Theory for triatomic systems. The Journal of Chemical Physics 1998, 109, 3792. [CrossRef]

${ }^{10}$ Lombardi, A.; Palazzetti, F.; Peroncelli, L.; Grossi, G.; Aquilanti, V.; Sevryuk, M. B. Fewbody quantum and many-body classical hyperspherical approaches to reactions and to cluster dynamics. Theoretical Chemistry Accounts 2007, 117, 709. [CrossRef]

${ }^{11}$ Remelt, J. Prediction and interpretation of collinear reactive scattering resonances by the diagonal corrected vibrational adiabatic hyperspherical model. Chemical Physics 1983, 79, 197. [CrossRef]

${ }^{12}$ Bastida, A.; Requena, A.; Zúniga, J. Generalized hyperspherical coordinates for molecular vibrations. The Journal of Physical Chemistry 1993, 97, 5831. [CrossRef]

${ }^{13}$ Manz, J.; Schor, H. H. R. A vibrational variational hyperspherical approach to the stretching states of triatomic ABA molecules. The Journal of Physical Chemistry 1996, 90, 2030. [CrossRef]
14 López, L. E. E.; Soares Neto, J. Hyperspherical Coordinates for Triatomic Molecules. International Journal of Theoretical Physics 2000, 39, 1129. [CrossRef] ${ }^{15}$ Aquilanti, V.; Cavalli, S.; G. Grossi, G. Hyperspherical coordinates for molecular dynamics by the method of trees and the mapping of potential energy surfaces for triatomic systems. The Journal of Chemical Physics 1986, 85, 1362. [CrossRef]

${ }^{16}$ Schöllkopf, W.; Toennies, J. P. Nondestructive Mass Selection of Small van der Waals Clusters. Science 1994, 266, 1345. [CrossRef]

${ }^{17}$ Cencek, W.; Patkowski, K.; Szalewicz, K. Full-configuration-interaction calculation of three-body nonadditive contribution to helium interaction potential. The Journal of Chemical Physics 2009, 131, 064105. [CrossRef]

${ }^{18}$ Cencek, W.; Jeziorska, M.; Akin-Ojo, O.; Szalewicz, K. Three-Body Contribution to the Helium Interaction Potential. The Journal of Chemical Physics A 2007, 111, 11311. [CrossRef]

${ }^{19}$ Navarro, O. A.; Beltran-Lopez, V. On the Convergence of Multibody Expansions for Short Range Intermolecular Forces. A SCF Calculation of $\mathrm{He}_{3}$ and $\mathrm{He}_{4}$ Systems. The Journal of Chemical Physics 1972, 56, 815. [CrossRef]

${ }^{20}$ Blume, D.; Greene, C. H. Monte Carlo hyperspherical description of helium cluster excited states. The Journal of Chemical Physics 2000, 112, 8053. [CrossRef]

${ }^{21}$ González-Lezana, T.; Rubayo-Soneira, J.; Miret-Artés, S.; Gianturco, F. A.; DelgadoBarrio, G.; Villarreal, P. Comparative configurational study for $\mathrm{He}, \mathrm{Ne}$, and $\mathrm{Ar}$ trimers. The Journal of Chemical Physics 1999, 110, 9000. [CrossRef]

${ }^{22}$ Cohen, M. J.; Murrell, J. N. An analytic function for the three-body potential of $\mathrm{He}_{3}$. Chemical Physics Letters 1996, 260, 371. [CrossRef]

${ }^{23}$ Blume, D.; Greene, C. H.; Esry, B. D. Comparative study of $\mathrm{He}_{3}, \mathrm{Ne}_{3}$, and $\mathrm{Ar}_{3}$ using hyperspherical coordinates. The Journal of Chemical Physics 2000, 113, 2145. [CrossRef] 
${ }^{24}$ Mitchell, K. A.; Littlejohn, R. G.; Derivation of planar three-body hyperspherical harmonics from monopole harmonics. Physical Review A 1997, 56, 83. [CrossRef]

${ }^{25}$ Barreto, P. R. P.; Vilela, A. F. A.; Lombardi, A.; Maciel, G. S.; Palazzetti, F.; Aquilanti, V. The Hydrogen Peroxide-Rare Gas Systems: Quantum Chemical Calculations and Hyperspherical Harmonic Representation of the Potential Energy Surface for Atom-Floppy Molecule Interactions. The Journal of Physical Chemistry A 2007, 111, 12754. [CrossRef]

${ }^{26}$ Barreto, P. R. P.; Albernaz, A. F.; Palazzetti, F.; Lombardi, A.; Grossi, G.; Aquilanti, V. Hyperspherical representation of potential energy surfaces: intermolecular interactions in tetra-atomic and penta-atomic systems. Physica Scripta 2011, 84, 028111. [CrossRef]

${ }^{27}$ Barreto, P. R. P.; Ribas, V. W.; Palazzetti, F. Potential Energy Surface for the $\mathrm{H}_{2} \mathrm{O}-\mathrm{H}_{2}$ System. The Journal of Physical Chemistry A 2009, 113, 15047. [CrossRef]

${ }^{28}$ Aquilanti, V.; Grossi, G.; Lombardi, A.; Maciel, G. S.; Palazzetti, F. The origin of chiral discrimination: supersonic molecular beam experiments and molecular dynamics simulations of collisional mechanisms. Physica Scripta 2008, 78, 058119. [CrossRef]

${ }^{29}$ Varshalovich, D. A.; Moskalev, A. N.; Khersonskii, V. K.; Quantum Theory of Angular Momentum, World Scientific: Singapore, 1988.

${ }^{30}$ Barreto, P. R. P.; Palazzetti, F.; Grossi, G.; Lombardi, A.; Maciel, G. S.; Vilela, A. F. A. Range and strength of intermolecular forces for van der Waals complexes of the type $\mathrm{H}_{2} \mathrm{Xn}$-Rg, with $\mathrm{X}=0, \mathrm{~S}$ and $n=1,2$. International Journal of Quantum Chemistry 2010, 110, 777. [CrossRef]

${ }^{31}$ Varandas, A. J. C. Extrapolation to the Complete Basis Set Limit without Counterpoise. The Pair Potential of Helium Revisited. The Journal of Physical Chemistry A, 2010, 114, 8505. [CrossRef]

${ }^{32}$ Werner, H.-J.; Knowles, P. J.; Lindh, R.; Schütz, M.; Celani, P.; Korona, T.; Manby, F. R.; Rauhut, G.; Amos, R. D.; Bernhardsson, A.; Berning, A.; Cooper, D. L.; Deegan, M. J. O.; Dobbyn, A. J.; Eckert, F.; Hampel, C.; Hetzer, G.; Lloyd, A. W.; McNicholas, S. J.; Meyer, W.; Mura, M. E.; Nicklass, A.; Palmieri, P.; Pitzer,
R.; Schumann, U.; Stoll, H.; Stone, A. J.; Tarroni, R.; Thorsteinsson, T. Molpro: a general-purpose quantum chemistry program package, version. Wiley Interdisciplinary Reviews: Computational Molecular Science 2012, 2, 242. [CrossRef]

${ }^{33}$ Dunning Jr., T. H., Gaussian basis sets for use in correlated molecular calculations. I. The atoms boron through neon and hydrogen. The Journal of Chemical Physics 1989, 90, 1007. [CrossRef]

${ }^{34}$ Woon, D. E.; Dunning Jr, T. H.Gaussian basis sets for use in correlated molecular calculations. IV. Calculation of static electrical response properties. The Journal of Chemical Physics 1994, 100, 2975. [CrossRef]

${ }^{35}$ Wilson, A. K.; Mourik, T. v.; Dunning Jr, T. H.Gaussian basis sets for use in correlated molecular calculations. VI. Sextuple zeta correlation consistent basis sets for boron through neon. Journal of Molecular Structure: THEOCHEM 1997, 388, 339. [CrossRef]

${ }^{36}$ Schuchardt, K. L.; Didier, B. T.; Elsethagen, T.; Sun, L.; Gurumoorthi, V.; Chase, J.; Li, J.; Windus, T. L. Basis Set Exchange: A Community Database for Computational Sciences. Journal of Chemical Information and Modeling 2007, 47, 1045. [CrossRef]

${ }^{37}$ Røeggen, I. Analytic functions for the three-body potential of the helium trimer. The Journal of Chemical Physics 2007, 126, 204303. [CrossRef]

${ }^{38}$ Szalewicz, K.; Monkhorst, H. J. The Journal of Chemical Physics 1981, 75, 5785. [CrossRef]

${ }^{39}$ van de Bovenkampa, J.; van Duijneveldt, F. B. $\mathrm{MRCl}$ calculations on the helium dimer employing an interaction optimized basis set. The Journal of Chemical Physics 1999, 110, 11141. [CrossRef]

${ }^{40}$ Klopper, W.; Noga, J. An explicitly correlated coupled cluster calculation of the helium-helium interatomic potential. The Journal of Chemical Physics 1995, 103, 6127. [CrossRef]

${ }^{41}$ Røeggen, I. An ab initio study of the fcc and hcp structures of helium. The Journal of Chemical Physics 2006, 124, 184502. [CrossRef]

${ }^{42}$ Lotrich, V. F.; Szalewicz, K. Perturbation theory of three-body exchange nonadditivity 
and application to helium trimer. The Journal of Chemical Physics 2000, 112, 112. [CrossRef]

43 Lewerenz, M. Structure and energetics of small helium clusters: Quantum simulations using a recent perturbational pair potential.
The Journal of Chemical Physics 1997, 106, 4596. [CrossRef]

${ }^{44}$ Bhattacharya, A.; Anderson, J. B. The interaction potential of a symmetric helium trimer. The Journal of Chemical Physics 1994, 100, 8999. [CrossRef] 